\title{
Visualisasi Peta Cagar Budaya menggunakan Geoportal Palapa pada Kawasan Situs Trowulan dan Gunung Penanggungan
}

\author{
Jayed Ali Bachtiar dan Lalu Muhamad Jaelani \\ Departemen Teknik Geomatika, Fakultas Teknik Sipil dan Perencanaan, Institut Teknologi Sepuluh \\ Nopember (ITS) \\ e-mail:1mjaelani@geodesy.its.ac.id
}

\begin{abstract}
Abstrak-Cagar budaya merupakan kekayaan budaya bangsa sebagai wujud kehidupan manusia, pemikiran dan perilaku yang penting untuk memahami sejarah sekaligus ilmu pengetahuan dan budaya nenek moyang kita. Di Jawa Timur ada dua kawasan cagar budaya yang telah dipilih oleh pemerintah: Penanggungan (mulai 14 Januari 2015) dan Trowulan (30 Desember 2013) sebagai cagar budaya tingkat provinsi dan nasional. Dalam penelitian ini, kami membangun infrastruktur data spasial geoportal untuk mengumpulkan, menyimpan dan memvisualisasikan distribusi spasial objek cagar budaya di kedua wilayah ini sebagai salah satu peran dalam menjaga kelestarian cagar budaya. Berdasarkan data geoportal, Situs Trowulan memiliki 80 artefak. Hal ini mengindikasikan bahwa kawasan Trowulan merupakan kawasan hunian. Sedangkan di situs Penanggungan, warisan didominasi oleh benda budaya berupa candi (sekitar 33 objek). Ini mungkin merupakan indikasi bahwa situs Penanggungan merupakan basis ritual pemujaan masyarakat purba. Secara umum, data cagar budaya yang telah berhasil dihimpun di Situs Trowulan dan Penanggungan jenis artefak sebanyak 84 lokasi, candi sebanyak 41 lokasi, goa sebanyak 3 lokasi, permukiman kuno sebanyak 5 lokasi, makam kuno sebanyak 6 lokasi, dan saluran air sebanyak 8 lokasi.
\end{abstract}

Kata kunci-Pelestarian Cagar Budaya, Geodatabase, Geoserver, Openlayer.

\section{PENDAHULUAN}

C AGAR Budaya adalah warisan budaya bersifat kebendaan berupa benda cagar budaya, bangunan cagar budaya, struktur cagar budaya, situs cagar budaya, dan kawasan cagar budaya di darat dan/atau di air yang perlu dilestarikan keberadaannya karena memiliki nilai penting bagi sejarah, ilmu pengetahuan, pendidikan, agama, dan/atau kebudayaan melalui proses penetapan [1]. Ada 4 (empat) hal penting yang melekat dan menjadi titik penekanan tentang cagar budaya sebagaimana terdapat dalam definisi cagar budaya yaitu: 1) warisan budaya yang bersifat kebendaan, 2) perlu dilestarikan, 3) memiliki nilai penting, dan 4) proses penetapan.

Direktur Pelestarian Cagar Budaya dan Permuseuman memberikan keterangan bahwa Cagar Budaya yang dimiliki Bangsa Indonesia perlu terus dilestarikan. Maka dari itu, upaya yang dapat dilakukan yaitu membuat sistem informasi geografis dalam wujud Geoportal Cagar Budaya yang memuat data-data cagar budaya dan tersimpan secara terpusat.

Geoportal adalah suatu sistem yang dapat terhubung kedalam jaringan internet yang digunakan untuk mengumpulkan, menyimpan, dan menampilkan data informasi bergeoreferensi atau data yang mengidentifikasikan lokasi kebutuhan penggunaan software Sistem Informasi Geografis [2]

Adapun tujuan dan sasaran dari penelitian ini antara lain adalah menyediakan sistem informasi berbasis keruangan (spasial) dalam bentuk geoportal yang menampilkan data cagar budaya situs trowulan dan situs penanggungan yang terjaga, dapat diperbarui (update) dan bisa diakses secara terbuka.

Adanya geoportal cagar budaya dapat memudahkan pemerintah untuk mendata, menghimpun, mengelola, dan memanfaatkan objek cagar budaya yang ada di kawasan cagar budaya, khususnya Kawasan Trowulan dan Gunung Penanggungan, Jawa Timur.

\section{METODOLOGI PENELITIAN}

\section{A. Lokasi Penelitian}

Penelitian ini mengambil studi kasus pada kawasan Situs Trowulan dan Situs Gunung Penanggungan yang keduanya berada di Kabupaten Mojokerto, Provinsi Jawa Timur. Kabupaten ini termasuk dalam daerah strategis di Jawa Timur yaitu wilayah "Gerbangkertasusila" terletak pada posisi $7^{\circ} 17^{\prime}$ sampai dengan $7^{\circ} 45^{\prime}$ Lintang Selatan dan $111^{\circ} 19^{\prime}$ sampai dengan 112³9' Bujur Timur dengan Zona UTM 49S[3].

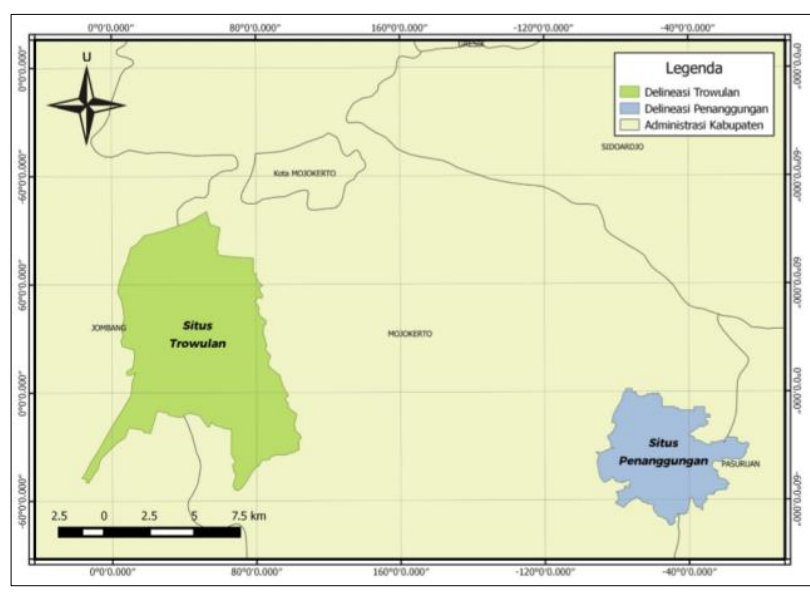

Gambar 1. Lokasi Penelitian

\section{B. Data and Peralatan}

1) Data

Adapun data yang digunakan dalam penelitian ini adalah data spasial berupa data shapefile terkait Bangunan, Struktur, Situs dan Kawasan Cagar Budaya dari Balai Pelestarian Cagar Budaya, dan batas administrasi wilayah dari Badan Informasi Geospasial. 
Data pendukung dalam penelitian ini adalah data atribut deskriptif tiap cagar budaya, data foto tiap cagar budaya, dan script openlayer untuk membangun tampilan Geoportal Cagar Budaya. Data pendukung tersebut diambil secara langsung ke lapangan maupun pencarian pada media daring.

\section{2) Peralatan}

Pengolahan data menggunakan perangkat lunak opensource yaitu QGIS sebagai pengolah data shapefile, PostGIS sebagai manajemen basis data, uDig sebagai pengatur gaya shapefile ke format XML, Geoserver sebagai penyedia layanan server data spasial secara daring, dan Geoportal sebagai media penyajian data dalam halaman web.

\section{Metode Penelitian}

\section{1) Tahap Penelitian}

Tahapan yang akan dilaksanakan dalam penelitian ini adalah sebagai berikut :

a. Pengumpulan Data

Data yang telah terkumpul yaitu data primer berupa data spasial dan data dokumentasi foto yang diambil langsung dari lapangan, maupun data sekunder dari hasil studi literaratur berupa data atribut yang terkait dengan data koordinat sebelumnya. Data spasial berupa data koordinat titik yang didapatkan dari pengukran GPS Handheld. GPS atau Global Positioning System menurut Sunyoto (2005) merupakan sebuah alat atau sistem yang dapat digunakan untuk menginformasikan penggunanya dimana dia berada (secara global) di permukaan bumi yang berbasiskan satelit [4].
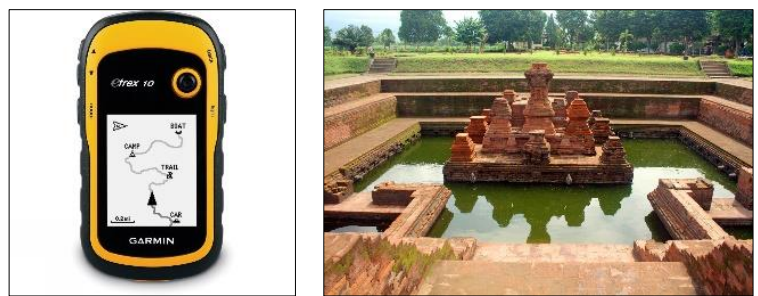

Gambar 2. (a) Alat GPS untuk mengambil data koordinat dan (b) Candi Tikus di Trowulan

\section{b. Pengolahan Data}

Tahapan pengolaan data pada penelitian ini ditunjukkan dalam diagram alir berikut :

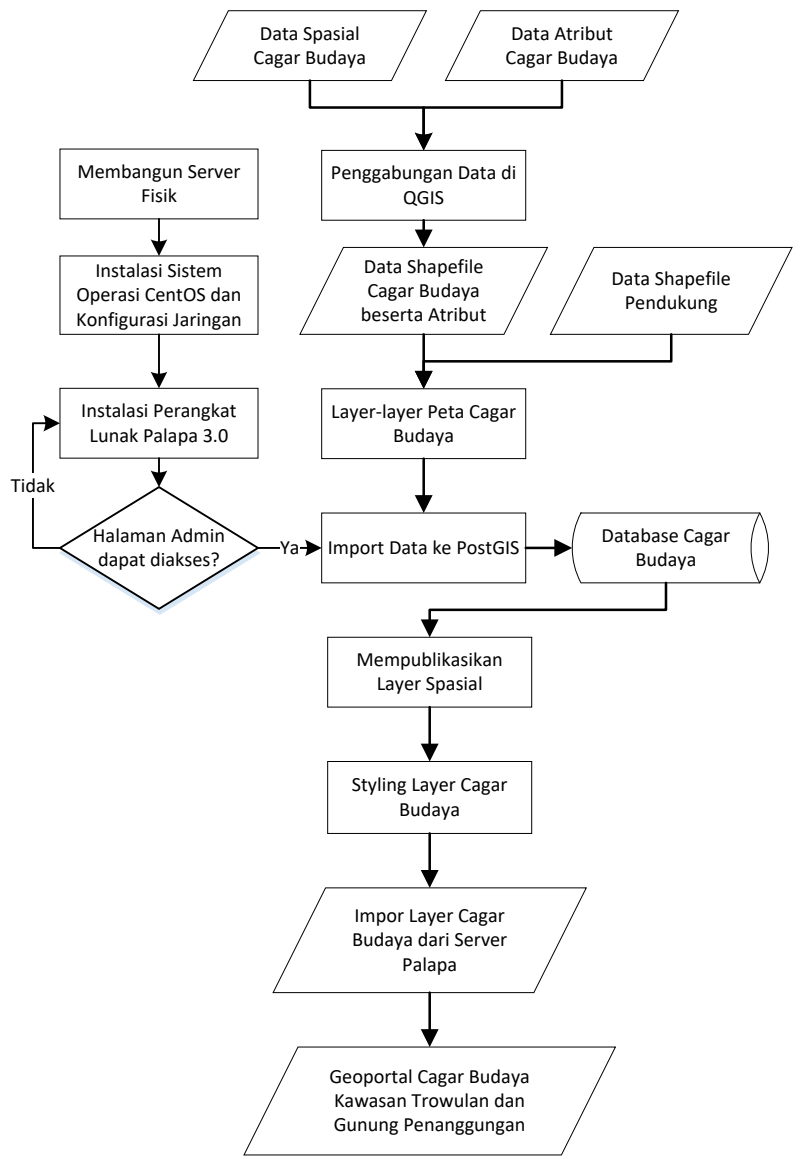

Gambar 3. Diagram Alir Pengolahan Data

Data yang awalnya berupa data analog dikonversikan menjadi data digital berupa data shapefile yang diolah dalam perangkat lunak QGIS. QGIS merupakan perangkat lunak SIG berbasis open source dan free (gratis) untuk keperluan pengolahan data geospasial [5]. Proses konversi data spasial menggunakan plugin QGIS XY Tools dan Point2One.

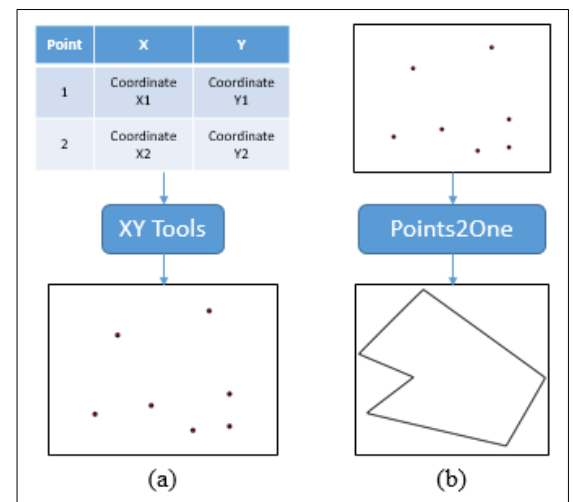

Gambar 4. Langkah-langkah (a) mengubah data excel menjadi titik koordinat (b) mengubah titik menjadi poligon

Proses berikutnya yaitu membuat basis data yang terdiri dari kumpulan shapefile yang mendukung konten geoportal. Pembuatan basis data menggunakan perangkat lunak PostgreSQL dengan ekstensi PostGIS. PostGIS adalah spatial extension untuk platform basis data (spatial) PostgreSQL. Spatial Basis data dapat menyimpan dan mengelola (manipulation) objek-objek spasial, seperti halnya pengelolaan data pada basis data umumnya [6].

Basis data menyimpan kumpulan shapefile dengan format tampilan standar. Maka dari itu untuk memperbaiki tampilan menggunakan perangkat lunak uDig. Hasil akhir dari pengolahan uDig adalah kode XML tiap shapefile. XML adalah 
bahasa markup yang dirancang khusus untuk penyampaian informasi melalui World Wide Web (WWW). XML merupakan suatu format data berbasis teks yang membantu Developer dan Provider dalam menggambarkan, mengirimkan dan menukarkan data yang terstruktur dari antara berbagai macam aplikasi kepada pengguna untuk keperluan manipulasi [7].

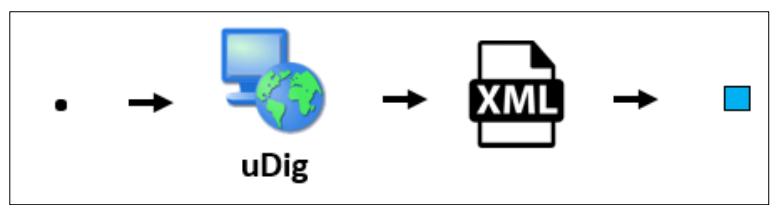

Gambar 5. Proses perubahan titik menggunakan Styled Layer Descriptor

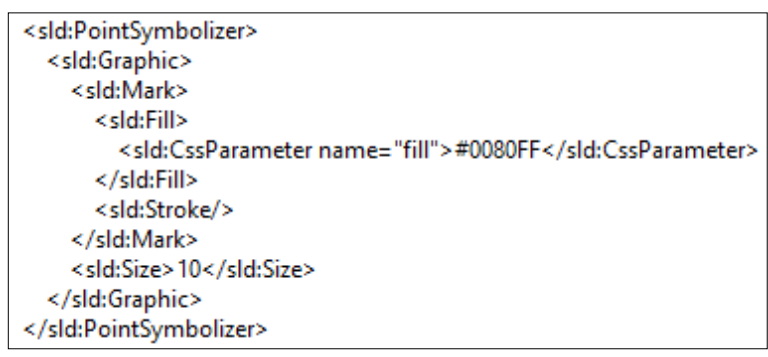

Gambar 6. Konten File SLD yang mengubah gaya titik

Kode XML hasil pengolahan uDig diinputkan ke perangkat lunak geoserver. GeoServer merupakan perangkat lunak server open source berbasis java yang memperbolehkan pengguna melihat dan mengubah data geospasial. GeoServer bersifat lintas sistem operasi (interoperable), dapat mempublikasikan data spasial dengan menggunakan standar terbuka [6].

Tahap akhir yaitu menampilkan hasil pengolahan data ke halaman web maka data dari geoserver dibuka dengan platform OpenLayers. Openlayers adalah aplikasi client berbasis javascript untuk menampilkan data peta pada web browser dan tidak tergantung pada web server yang digunakan. Openlayers mengimplementasikan JavaScript API yang digunakan untuk membangun aplikasi GIS berbasis web. Openlayers mirip dengan Google Maps and MSN Virtual Earth API, dengan satu perbedaan penting yaitu OpenLayers adalah perangkat lunak gratis, yang dikembangkan untuk dan oleh komunitas perangkat lunak Open Source [8].

\section{c. Penyajian Data}

Hasil akhir dari penelitian ini adalah sebuah Geoportal Web Cagar Budaya di Kawasan Trowulan dan Gunung Penanggungan di Kabupaten Mojokerto. Web adalah salah satu layanan TCP/IP yang paling populer dalam memberikan kemudahan informasi[9]. Web bekerja dengan konsep client side, yaitu suatu sistem yang melakukan permintaan data atau layanan ke webserver. Kemudian, webserver akan menyediakan data atau layanan yang diminta oleh web client. Komunikasi antara webserver dengan web client dengan mengirimkan dan menerima dokumen web melalui suatu protokol yang disebut dengan Hypertext Transfer Protocol (HTTP). HTTP berfungsi mendefinisikan dan menjelaskan bagaimana webserver dan web client berinteraksi dalam mengirimkan dan menerima dokumen web.

\section{HASIL DAN ANALISA}

\section{A. Basis Data pada PostGIS}

Hasil pengolahan data spasial cagar budaya dari QGIS dismpan dalam format shapefile. Data shapefile kemudian diimport ke dalam sistem basis data PostGIS untuk mendapatkan identitas geom. Identitas geom inilah yang akan digunakan pada proses-proses berikutnya selama pengembangan geoportal. Berikut merupakan sampel data geom hasil impor data shapefile ke PostGIS.

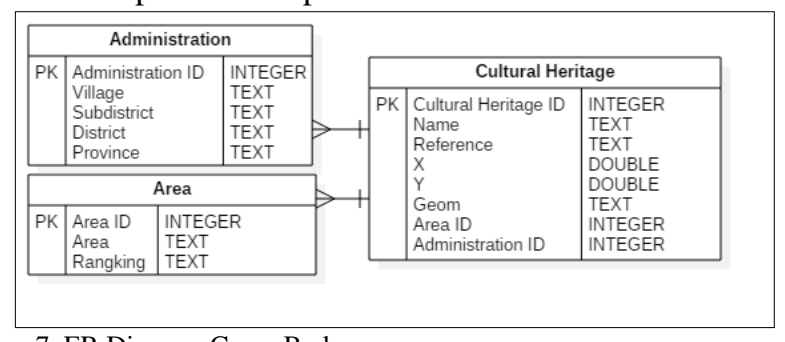

Gambar 7. ER Diagram Cagar Budaya

Setiap jenis data geometri baik titik, garis, ataupun poligon akan dikonversi kedalam identitas geom. Sebab identitas geom merupakan identitas yang dapat dibaca oleh perangkat lunak yang tergabung dalam Opengeo Suite sebagai pengganti file berformat shapefile.

\section{B. Visualisasi Peta Cagar Budaya pada Geoportal}

Keluaran dari Geoserver adalah data peta dengan Framework OpenLayer dan dibuka dengan Geoportal. Framework OpenLayer tersebut merupakan sumber data yang dapat dibuka melalui geoportal yang dikembangkan. Berikut merupakan tampilan data Situs Trowulan dalam Geoportal :

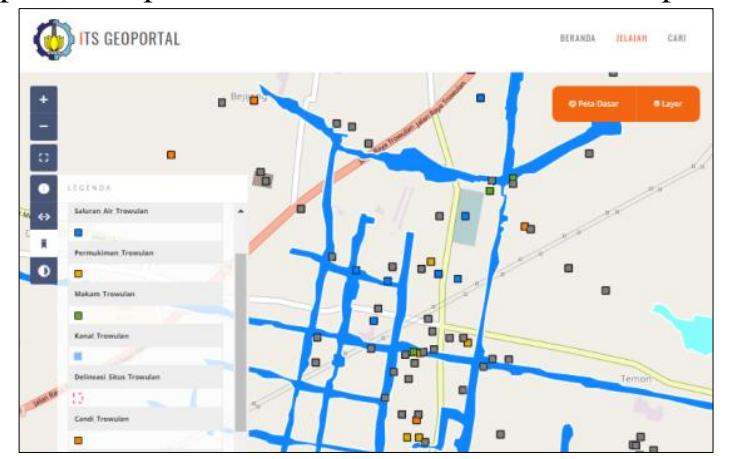

Gambar 8. Situs Trowulan pada Geoportal

Lalu untuk tampilan data Situs Penanggungan dalam Geoportal adalah sebagai berikut :

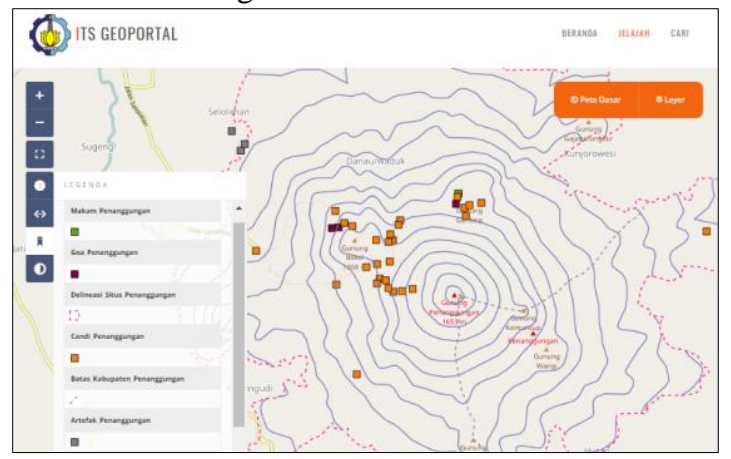

Gambar 9. Situs Penanggungan pada Geoportal

\section{Analisa Data Cagar Budaya}

Hasil rekapitulasi cagar budaya yang terdapat pada Situs Trowulan dan Situs Penanggungan akan ditunjukkan dalam tabel 1 berikut :

Tabel 1.

Rekapitulasi Cagar Budaya

\begin{tabular}{clcc}
\hline \hline No & $\begin{array}{c}\text { Jenis Cagar } \\
\text { Budaya }\end{array}$ & $\begin{array}{c}\text { Situs } \\
\text { Trowulan }\end{array}$ & $\begin{array}{c}\text { Situs } \\
\text { Penanggungan }\end{array}$ \\
\hline $\mathbf{1}$ & Candi & 8 & 33 \\
2 & Gua & 0 & 3 \\
\hline \hline
\end{tabular}




\begin{tabular}{rlcc}
\hline \hline $\mathbf{3}$ & Makam Kuno & 5 & 1 \\
$\mathbf{4}$ & Permukiman & 5 & 0 \\
& Kuno & 8 & 0 \\
$\mathbf{5}$ & Saluran Air & 80 & 4 \\
$\mathbf{6}$ & Artefak & 106 & 41 \\
& Total & \\
\hline \hline
\end{tabular}

Dari hasil rekapitulasi cagar budaya, di kawasan Situs Trowulan terdapat cagar budaya berjumlah 101 buah, sedangkan di Situs Penanggungan terdapat 39 buah cagar budaya.

Pada Situs Trowulan terdapat 5 jenis cagar budaya yaitu Candi, Makam Kuno, Pemukiman Kuno, Saluran Air, dan Artefak. Situs Penanggungan terdapat 4 jenis cagar budaya yaitu Candi, Gua, Makam Kuno dan Artefak. Jika diperbandingkan, Situs Trowulan memiliki temuan artefak yang paling banyak yaitu sebanyak 80 buah. Artefak ditemukan diberbagai lokasi yang diperkirakan dulunya merupakan pusat kegiatan permukiman masyarakat. Relief dari reruntuhan peninggalan Kerajaan Majapahit menunjukkan tatanan permukiman di masa kuno[10]. Berbeda dengan wilayah Situs Penanggungan, temuan paling banyak adalah cagar budaya berupa candi yaitu sebanyak 33 buah. Peranan gunung Penanggungan sebagai sebuah mandala sangatlah besar dengan ditemukannya peninggalan berupa pathirtan, gua pertapaan serta bangunan suci (candi) sebagai penanda bahwa terdapat komunitas- kounitas keagamaan yang tersebar di tempat tersebut Hal tersebut menunjukkan bahwa Situs Penanggungan merupakan basis untuk ritual ibadah masyarakat kuno[11].

\section{KESIMPULAN}

Dari hasil pengembangan geoportal cagar budaya kawasan Situs Trowulan dan Situs Penanggungan, maka dapat disimpulkan bahwa :

1. Telah berhasil dikembangkan geoportal cagar budaya kawasan Situs Trowulan dan Situs Penanggungan menggunakan paket perangkat lunak opensource PALAPA 3.0. Geoportal yang dikembangkan dapat diakses oleh publik dengan alamat http://peta.its.ac.id/. Permasalahan yang muncul pada penelitian ini yaitu sistem Geoportal tidak dapat menampilkan data raster seperti .jpg dan .png untuk merepresentasikan suatu titik sehingga Geoportal tidak dapat menampilkan foto objek maupun mengubah icon titik. Kelebihan dari Palapa yaitu kemampuannya mendukung web map service (WMS) sehingga dapat mengimpor peta dari berbagai WMS lain diseluruh dunia.

2. Telah berhasil dihimpun data cagar budaya di Situs Trowulan dan Penanggungan jenis artefak sebanyak 84 lokasi, candi sebanyak 41 lokasi, goa sebanyak 3 lokasi, permukiman kuno sebanyak 5 lokasi, makam kuno sebanyak 6 lokasi, dan saluran air sebanyak 8 lokasi.

3. Data cagar budaya dapat diunduh di halaman Cari pada Geoportal. Data yang ada telah dilengkapi dengan informasi metadata pada setiap layernya. Data Situs Trowulan dan Situs Penanggungan didapatkan dari sumber yang terpercaya. Situs Trowulan didapatkan dari Balai Pelestarian Cagar Budaya (BPCB) Jawa Timur sedangkan Situs Penanggungan didapatkan dari Penanggungan Center yang merupakan instansi resmi yang ditunjuk oleh BPCB untuk menghimpun data cagar budaya di kawasan Situs Penanggungan.

\section{DAFTAR PUSTAKA}

[1] Kementerian Pendidikan dan Kebudayaan, Undang-Undang Republik Indonesia Nomor 11 Tahun 2010 Tentang Cagar Budaya. 2010.

[2] M. Painho, "WebGIS as a Teaching Tool," Proc. ESRI UC, 2001.

[3] K. Anwar, "Potensi Wisata Budaya Situs Sejarah Peninggalan Kerajaan Majapahit di Trowulan Mojokerto,” p. 105, 2009.

[4] Afrizal, A. Sukmaaji, and T. Sutanto, “Android Personel Monitoring Location pada Institusi Kepolisian Berbasis Web," vol. 3, no. 2, 2013.

[5] P. Oswald and R. Astrini, "Modul Pelatihan Quantum GIS Tingkat Dasar," 2012.

[6] Kementerian Riset dan Teknologi, "Opengeo Suite dan InaGeoportal," vol. 2011, no. 1997, pp. 2007-2010, 2009.

[7] F. Samopa, D. H. Murti, and O. Oktanio, "Sistem Query pada Dokumen XML dengan Menggunakan Bahasa SQL,” JUTI J. Ilm. Teknol. Inf., vol. 4, no. 2, p. 133, Jul. 2005.

[8] Budiawan, "Aplikasi GIS Berbasis WEB Menggunakan Geoserver pada Sistem Informasi Trafo Gardu Induk di PLN Surabaya," Undergrad. Thesis, Informatics Eng. RSIf 025.0691 Bud a, 2010, 2010.

[9] A. A. Hartanto and O. W. Purbo, Buku Pintar Internet: Teknologi ELearning Berbasis PHP dan MySQL. Jakarta: Elex Media Komputindo, 2002.

[10] T. Tribinuka, "Rekonstruksi Arsitektur Kerajaan Majapahit dari Relief, Artefak dan Situs Bersejarah,” pp. 19-24, 2014.

[11] A. Nurwahyu, S. Muhammad, and Y. H. Pamungkas, "Kajian Arsitektur Dan Fungsi Candi Kendalisada Di Situs Gunung Penanggungan," vol. 4, no. 3, pp. 1035-1045, 2016. 